Foad Buazar ${ }^{1, \star}$, Sajjad Sweidi ${ }^{2}$, Mohammad Badri ${ }^{2}$ and Feisal Kroushawi ${ }^{2}$

\title{
Biofabrication of highly pure copper oxide nanoparticles using wheat seed extract and their catalytic activity: A mechanistic approach
}

https://doi.org/10.1515/gps-2019-0040

Received January 23, 2019; accepted May 26, 2019.

Abstract: A facile novel green methodology is presented for the synthesis of highly stable and well-dispersed copper oxide nanoparticles using aqueous wheat seed extract. Under optimal reaction conditions, the wheat seed extract-derived electron-rich biomolecules were functioned as a reducing and capping/stabilizing agent. The ultraviolet-visible absorption peak at $300 \mathrm{~nm}$ was confirmed the formation of copper oxide nanoparticles. Fourier-transform infrared spectroscopy analysis determined $\mathrm{Cu}-\mathrm{O}$ bonds in nanosample, indicating the active role of functional groups in the wheat seed extract in bioreduction of $\mathrm{Cu}$ cations. X-ray diffraction pattern results demonstrated the monoclinic structure of highly pure biosynthesized copper oxide nanoparticles with a crystallite size of $20.76 \mathrm{~nm}$. The stability of copper oxide nanoparticles was confirmed after 3 months' storage of product with no sedimentation or suspension. Transmission electron microscopy results showed the spherical shape of nanoparticle with an average size of $22 \pm 1.5 \mathrm{~nm}$. X-ray photoelectron spectroscopy analyses revealed only copper and oxygen elements in the sample, confirming the purity of copper oxide nanoparticles. Bio-assisted copper oxide nanoparticles demonstrated significant catalytic efficiency and reusability toward 4-nitrophenol removal by an average of $97.6 \%$ from aqueous solutions after successive 5 days' exposure to UV irradiation.

Keywords: copper oxide nanoparticle; wheat seed extract; biosynthesis; 4-nitrophenol removal; formation mechanism

\footnotetext{
* Corresponding author: Foad Buazar, Department of Marine Chemistry, Khorramshahr University of Marine Science and Technology, P.O. Box 669, Khorramshahr, Iran, e-mail: fb@kmsu.ac.ir

Sajjad Sweidi, Mohammad Badri, Feisal Kroushawi, Department of Marine Chemistry, Khorramshahr University of Marine Science and Technology, P.0. Box 669, Khorramshahr, Iran
}

\author{
Abbreviations \\ $\mathrm{CuO}$ Copper Oxide \\ FTIR Fourier-transform infrared spectroscopy \\ NPs Nanoparticles \\ 4-NP 4-Nitrophenol \\ SEM Scanning Electron Microscope \\ TEM Transmission Electron Microscope \\ T. Triticum \\ XPS X-Ray Photoelectron Spectroscopy \\ XRD X-Ray Powder Diffraction \\ UV-Vis Visible and Ultraviolet Spectroscopy
}

\section{Introduction}

Nanoparticles owing to high surface area and a tiny particle size show inimitable material characteristics in comparison with bulk materials, which make them high in demand and widely applied area for miscellaneous applications in recent years. Presently, a considerable number of physical and chemical procedures were presented to fabricate the various types of nanoscale particles with different shape and size. Despite their popularity, they are high cost and often contain toxic materials (e.g. solvent, the reducing agent, acid and base reagents) which potentially expose the environment to serious health hazards; so that restricts their advantages. Whereas biological procedures are non-toxic, high atom economy, straightforward methodology and most importantly they are environment-friendly [1]. Hence, recent researches have been attempted to employ nature-based sources such as plants extracts [2,3], fungi [4], bacteria [5], and marine organisms [6], as sustainable alternative methods toward green nanoparticles fabrication [7]. Owing to presence highly active bio-organic molecules in plants, eco-friendly plant-based methodologies such as roots, flowers, seeds, leaves, bark, and fruits, have emerged as extremely promising biological factories for the formation of the diverse range of inorganic 
nanoparticles [8]. Apparently, their active biomolecules most likely comprise amino, hydroxyl, and carboxyl biofunctional groups which would function a dual role as a reductant of metal salts and as protective agents to form a stabilizing layer on the biosynthesized nanoparticles [9].

Copper oxide nanoparticles (CuO NPs) and their derivatives as a type of metal oxide nanoparticles due to fair stability, cost-effectiveness and readily available compared to other expensive noble metals like $\mathrm{Au}, \mathrm{Pt}$, and $\mathrm{Ag}$ are broadly used in many applications such as a colorant in many ceramics applications, including the preparation of slips and glazes [10], batteries, catalyst for chemical reactions [11], solar cell [12], chemical sensor $[13,14]$, absorbent [15], thermal conductivity enhancer [16], antifouling properties [17], wastewater treatment $[18,19]$, thermal conductivity and anti-oxidation properties [20], bio-control agent [21], drug delivery [22], anticancer activity [23], and efficient anti-microbacterial agent $[24,25]$.

There are a wide variety of traditional chemical and physical methods for $\mathrm{CuO}$ NPs fabrication including electrochemical methods [26], sonochemical [27], alcohothermal [28], hydrothermal decomposition [29], precipitation [30], polyol [31], and gamma radiation [32]. To avoid serious environmental hazards and health effects of chemical synthesis methods, several reports on phyto-assisted synthesis of $\mathrm{CuO}$ NPs by different parts of plant extracts have been published including abutilon indicum leaf [33], Saraca indica leaves [34], Rheum palmatum L. root [35], Aglaia elaeagnoidea flower [36], Malus domestica leaf [37], and green pea [38].

Common wheat (Triticum aestivum), bread wheat, is an annual cereal grain cultivated in greater quantities for its seed. It considers a global staple food with the highest monetary yield [39]. Wheat is the major source of carbohydrate biomolecules such as starch and simple electron-rich reducing sugars (e.g. glucose, and fructose) [40]. Therefore, the goal of this study is to present an alternative new abundant natural source based on 12 principles of green chemistry for the rapid one-step fabrication of highly pure and safer CuO NPs by aqueous extract of wheat seed. Size, purity, shape and surface chemistry of as-prepared $\mathrm{CuO}$ NPs were scrutinized through Visible and Ultraviolet spectroscopy (UV-Vis), Fourier-transform infrared spectroscopy (FTIR), X-ray photoelectron spectroscopy (XPS), X-ray powder diffraction (XRD), scanning electron microscope (SEM) and transmission electron microscope (TEM).

\section{Experimental}

\subsection{Materials}

Copper (II) sulfate pentahydrate $\left(\mathrm{CuSO}_{4} \cdot 5 \mathrm{H}_{2} \mathrm{O}\right)$ was acquired from Sigma-Aldrich supplier (USA) and utilized without further purification. Deionized (DI) water was used in all experiment steps for making molar solutions, washing, and dilution.

\subsection{Preparation of the aqueous wheat seed extract}

The aqueous extract of wheat seeds was acquired utilizing a facile soaking extraction method [41]. Generally, healthy wheat grains Triticum aestivum (T. aestivum) were collected at their harvest time from the local wheat field in Ahwaz ( $\left.31^{\circ} 19^{\prime} 8.44^{\prime \prime} \mathrm{N}, 48^{\circ} 41^{\prime} 3.12^{\prime \prime} \mathrm{E}\right)$, Iran. To obtain the unblemished powder, the surfaces of $T$. aestivum seeds were thoroughly rinsed several times with distilled water to eliminate possible extraneous impurities, for instance, plant detritus, waste or debris of any kind. To reduce seeds moisture content, harvested wheat grain specimens were dehydrated at $60^{\circ} \mathrm{C}$ for 2 days and grounded to the fine powder using mini flour mill. Afterward, $5 \mathrm{~g}$ of sterilized seed powder was soaked in $300 \mathrm{~mL}$ of sterile distilled water to prepare an appropriate liquid extract. At a moderate temperature of $80^{\circ} \mathrm{C}$, the solution was gently heated for $10 \mathrm{~min}$. Finally, the product was centrifuged at $5000 \mathrm{rpm}$, filtered, and the obtained supernatant liquid was stored in the fridge at $5^{\circ} \mathrm{C}$ for more experimental tests.

\subsection{Green synthesis of CuO NPs}

In the characteristic recipe of wheat seed-mediated biological synthesis of $\mathrm{CuO}$ NPs, in an Erlenmeyer flask, $10 \mathrm{~mL}$ of liquid T. aestivum extract was added into $90 \mathrm{~mL}$ of $0.01 \mathrm{M}$ aqueous solution of copper (II) sulfate. The resultant was continually stirred for $1 \mathrm{~h}$ at room temperature of $25^{\circ} \mathrm{C}$ to obtain a homogenous mixture in composition. Then, the solution was sonicated for $10 \mathrm{~min}$ and gently heated to $70^{\circ} \mathrm{C}$ for $20 \mathrm{~min}$. After $10 \mathrm{~min}$ of the last heating process, the steady variation in color from dark blue to dark brown into solution was witnessed as an initial visual inspection of bioreduction copper ions to CuO NPs. The resultant was centrifuged at $12000 \mathrm{rpm}$ for $10 \mathrm{~min}$, dried in the furnace at $95^{\circ} \mathrm{C}$ for $120 \mathrm{~min}$ and the precipitate 
of $\mathrm{CuO}$ nanopowder was collected (Scheme 1). In so doing, the reaction was optimized by changing wheat seed extract concentrations, $\mathrm{pH}$, salt precursor concentration, and contact time (see Supplementary material).

\subsection{The characterization of CuO NPs}

Crystal structure of the bioprepared $\mathrm{CuO}$ NPs X-ray was probed using XRD pattern (MPD from analytical). TEM (ZeissEM10C-100KV-Germany) and SEM (Zeiss-Sigma-Germany)

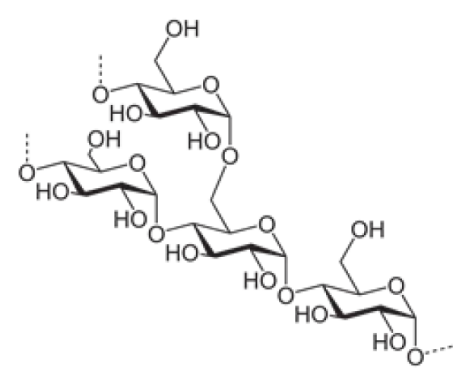

Starch (Amylopectin)

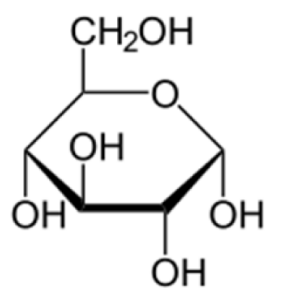

Glocose

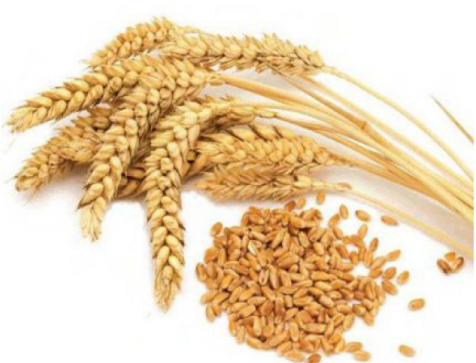

Wheat grain

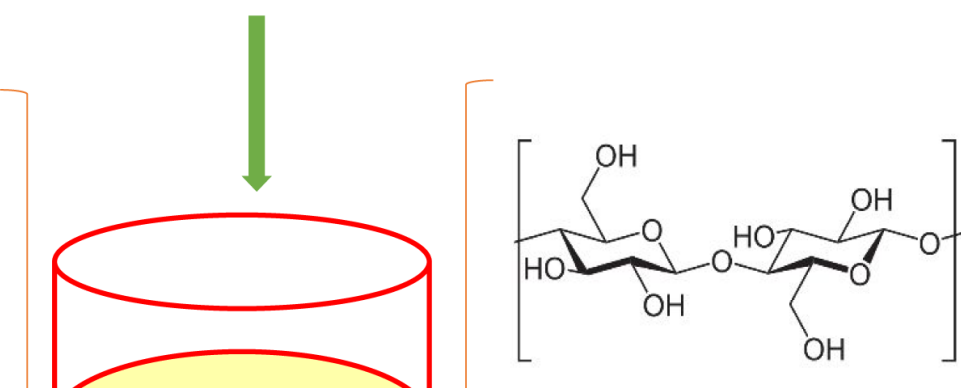

Other Carbohydrates

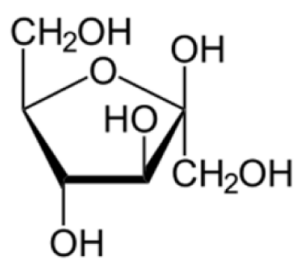

Fructose

$\mathrm{T}=70^{\circ} \mathrm{C}$ $\mathrm{pH} \cong 7$ $\mathrm{t}=30 \mathrm{~min}$

\section{$\mathrm{CuSO}_{4}$}

solution

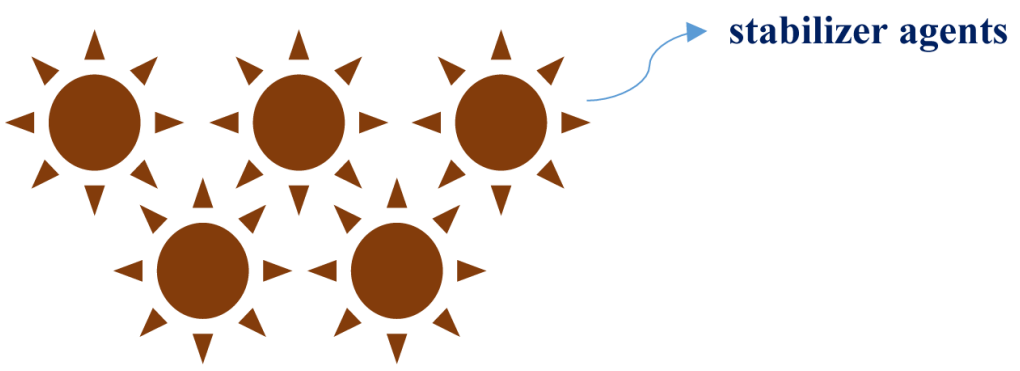

$\mathrm{CuONps}$

Scheme 1: One-pot green synthesis of $\mathrm{CuO}$ nanoparticles using aqueous wheat extract. 
techniques were used to examine the morphology and particle size of the sample. The surface chemistry of the CuO NPs was investigated using FTIR (VEATOR22-Burker Germany) by a $\mathrm{KBr}$ pellet. The formation of $\mathrm{CuO}$ NPs was recorded as a function of reaction process time via UV-Vis (Analytic JenaGermany) in the range of 200-700 nm.

\subsection{Catalytic elimination of 4-nitrophenol}

To examine the catalytic activity of the biofabricated $\mathrm{CuO}$ NPs, in a $100 \mathrm{~mL}$ beaker, a $25 \mathrm{~mL}$ of $2 \mathrm{mM}$ 4-nitrophenol (4-NP) as a modal pollutant was mixed with $0.2 \mathrm{~g} \mathrm{NaBH}_{4}$ under gently stirring for $5 \mathrm{~min}$. Then, $10 \mathrm{mg}$ of $\mathrm{CuO}$ NPs were added as catalysts to the reaction mixture under constant stirring at room temperature of $25^{\circ} \mathrm{C}$ until the yellow color of solution turns to colorless. Next, $2.0 \mathrm{~mL}$ sample of the solution was taken out and diluted to $20 \mathrm{~mL}$ for further UV-Vis absorption analysis at certain intervals in the recorded scanning range of $200-700 \mathrm{~nm}$. The elimination process of 4-NP was probed via monitoring the alterations in intensity of the major peak at $315 \mathrm{~nm}$ as a function of time.

\section{Result and discussion}

\subsection{UV-visible spectrum of CuO NPs}

UV-visible spectra ofCuONPs formation via the supernatant of the $T$. aestivum extract and crude $T$. aestivum extract were shown in Figure 1. CuO NPs has illustrated a relatively broad absorption peak at $305 \mathrm{~nm}$ most likely attributed to surface plasmon resonance (SPR) of $\mathrm{CuO}$ semiconductor excitation [42]. Using Tauc relation [43], the optical band gap energy $\left(E_{\mathrm{g}}, \mathrm{eV}\right)$ of green $\mathrm{CuO}$ NPs achieved $4.13 \mathrm{eV}$ (Figure 1c), which was higher value than the corresponding bulk $\mathrm{CuO}(\sim 2.1 \mathrm{eV})$ [44]. The increasing $\mathrm{Eg}$ is attributed to decreasing particle size, thereby, CuO NPs might be
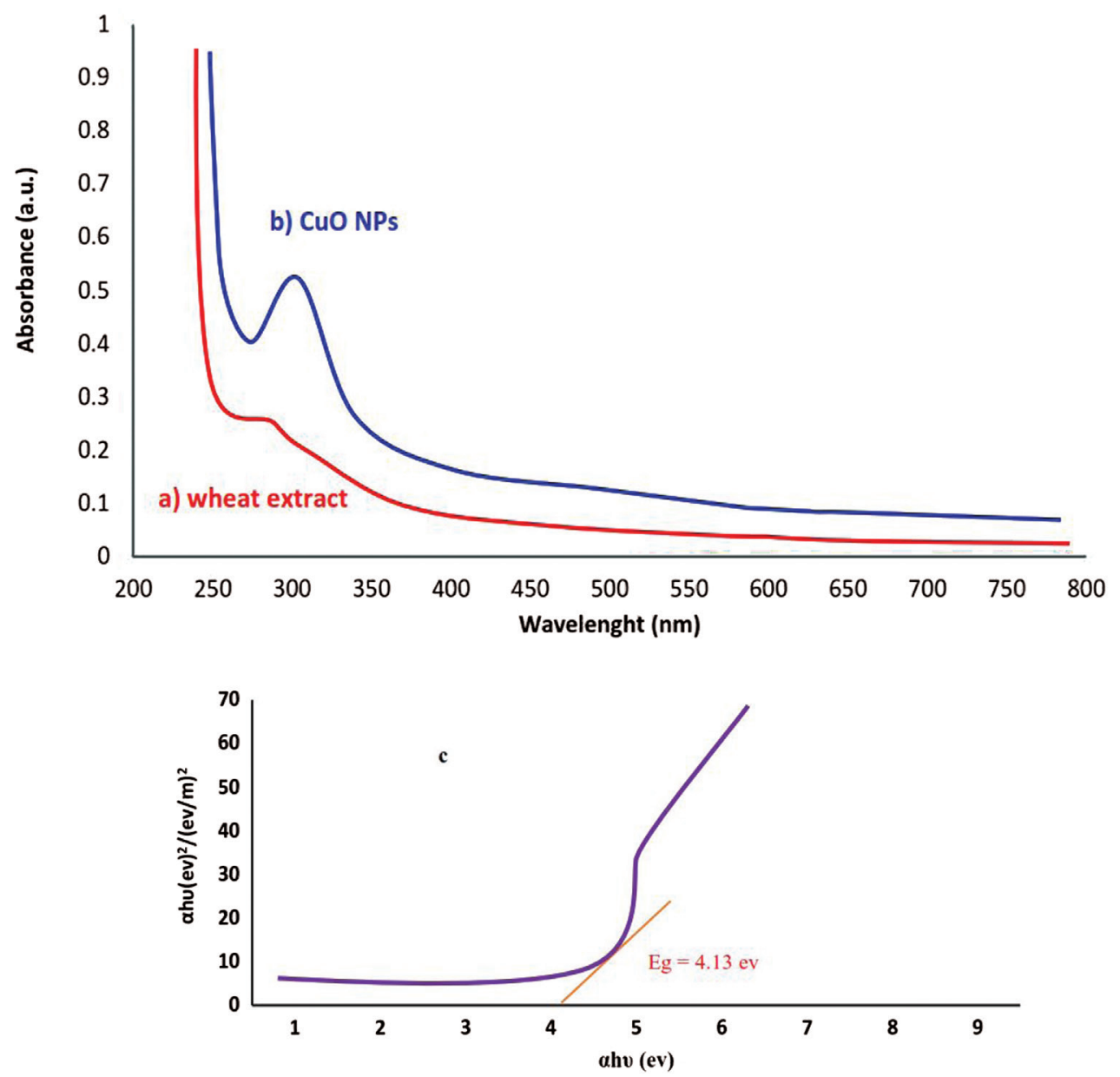

Figure 1: UV-vis spectra of (a) aqueous wheat extract, (b) biofabricated CuO NPs, and (c) Tauc plot of CuO NPs. 


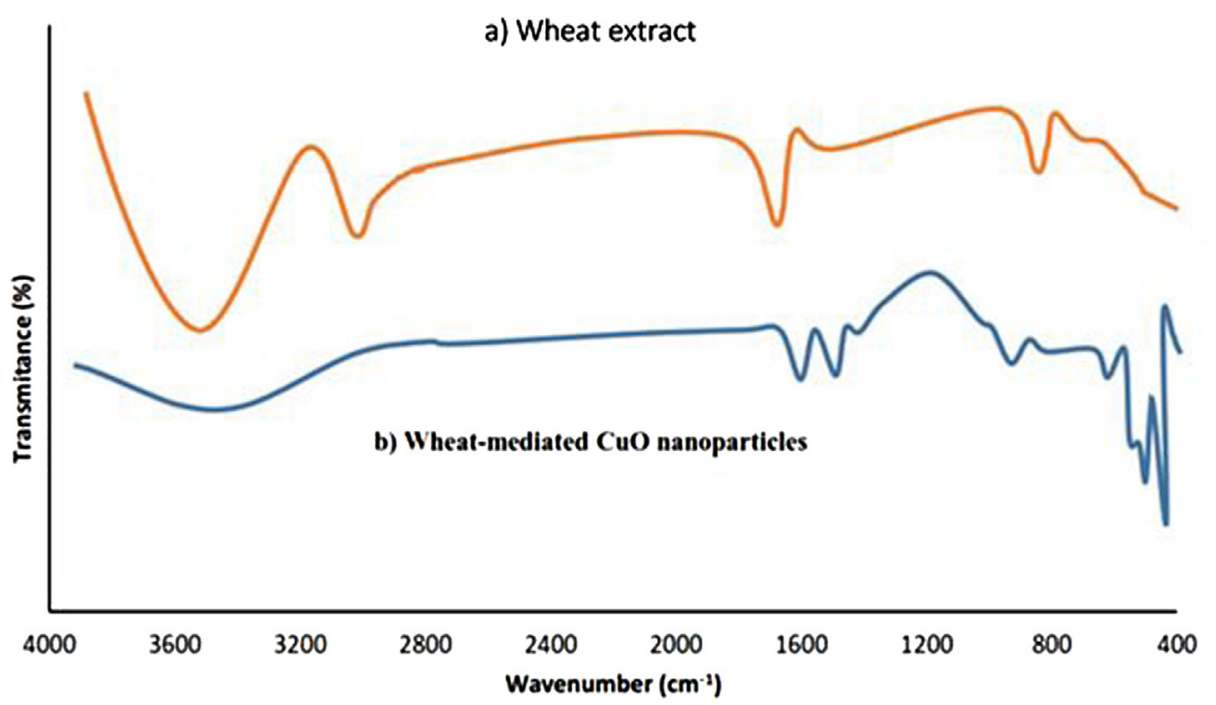

Figure 2: (a) FTIR spectra of wheat extract and (b) wheat-mediated CuO NPs.

used as an ideal harvester for solar irradiations and an effective photocatalyst for environmental remediation [45]. Moreover, UV-vis instrument displays no absorbance peak for pristine wheat seed extract as a blank sample (Figure 1). These observations obviously induce that active organic biomolecules in aqueous extract of wheat seeds were significantly engaged in the reduction of copper cations, $\mathrm{Cu}^{2+}$, to $\mathrm{CuO}$ NPs.

\subsection{FTIR results}

FTIR is a valuable technique to determine active biofunctional groups of wheat seed extract engaged in the copper ions bioreduction and their possible changes after $\mathrm{CuO}$ NPs synthesis. CuO NPs and aqueous wheat seed extract reveal a number of bands in different areas of FTIR spectrum, hence demonstrating the tangible dual role of abundant hydroxyls functional groups for synchronous bioreduction of $\mathrm{Cu}$ cations and stabilization of as-formed $\mathrm{CuO}$ NPs (Figure 2) [46]. In aqueous wheat seed extract (Figure 2a), The 3420, 1640, and $811 \mathrm{~cm}^{-1}$ bands were ascribed to $\mathrm{O}-\mathrm{H}$ (hydroxyl), $\mathrm{C}=\mathrm{O}$ (carbonyl), and out of plane $\mathrm{C}-\mathrm{H}$ stretching, respectively. While FTIR spectrum of $\mathrm{CuO}$ NPs shows reasonable changes in intensity and position of above peaks along with the presence of new bands in the sample. Bands of 3328, 1552, 1433 and $1032 \mathrm{~cm}^{-1}$, were attributed to $\mathrm{O}-\mathrm{H}$ (polyol), $\mathrm{N}-\mathrm{H}$ (amino acid), $\mathrm{C}-\mathrm{O}-$ (glycosidic linkage), and aromatic or aliphatic $\mathrm{C}-\mathrm{O}$ stretching, respectively (Figure $4 \mathrm{~b}$ ). In the FTIR spectrum, the characteristic frequencies of $\mathrm{CuO}$ bonds of $\mathrm{CuO}$ NPs were appeared in $483(\mathrm{Cu}-\mathrm{O}$ symmetric stretching), 541 (asymmetric stretching), and $672 \mathrm{~cm}^{-1}$ (wagging) bands, respectively (Figure 2b) [47]. These results evidently indicate an electrostatic interaction between electron-rich amino, ketonic $\mathrm{C}=\mathrm{O}$ and alcoholic $\mathrm{OH}$ groups present in wheat seed extract and $\mathrm{Cu}$ ions which in turn leads to biosynthesize of CuO NPs [2].

\subsection{XRD examination of CuO NPs}

The XRD pattern of biogenic CuO NPs is depicted in Figure 3. The presence of the quite clear and fairly sharp peaks with different $2 \theta$ values clearly demonstrated the highly crystalline structure of bio-assisted $\mathrm{CuO}$ nanopowder [34]. The analysis of assigned crystal planes (Bragg reflection) of rather strong peaks can be indexed to the monoclinic phase of CuO (JCPDS01-080-1268) [48]. Similarly, X-ray diffraction of biosynthesized CuO NPs via an aqueous black bean [23], and Aglaia elaeagnoidea flowers extracts revealed that the particles are monoclinic in nature [36]. XRD pattern exhibited no extra peaks, indicating the green $\mathrm{CuO}$ NPs were highly purified. Using the Debye-Scherrer formula, the crystal size of $\mathrm{CuO}$ NPs of the highest peak at 2 theta $=38.66^{\circ}$ (111) was found to be $20.76 \mathrm{~nm}$ which fairly smaller than CuO NPs (90.0, 52.0, and $59.8 \mathrm{~nm}$ ) synthesized by wet chemical precipitation [49], starch extract [50], and flower extract methods, respectively [36].

\subsection{XPS analysis of CuO NPs}

The purity of the bio-processed $\mathrm{CuO}$ nanoproduct was further scrutinized by means of XPS technique as shown in Figure 4. The XPS binding energy at 933.7 and $950.2 \mathrm{eV}$ 
would assign respectively to $\mathrm{Cu} 2 \mathrm{p}_{3 / 2}$ and $\mathrm{Cu} 2 \mathrm{p}_{1 / 2}$ (Figure 4a). The sharp peak at $530.6 \mathrm{eV}$ is anticipated to $\mathrm{O}$ atom bond to copper (II), producing $\mathrm{CuO}$ NPs

(Figure 4b). These findings are consistent with literature reports [51], confirming the purity of bioproduced $\mathrm{CuO}$ NPs. Likewise, Rovani et al. have reported the green synthesis of highly pure silica nanoparticles with high adsorption capacity using sugarcane waste ash

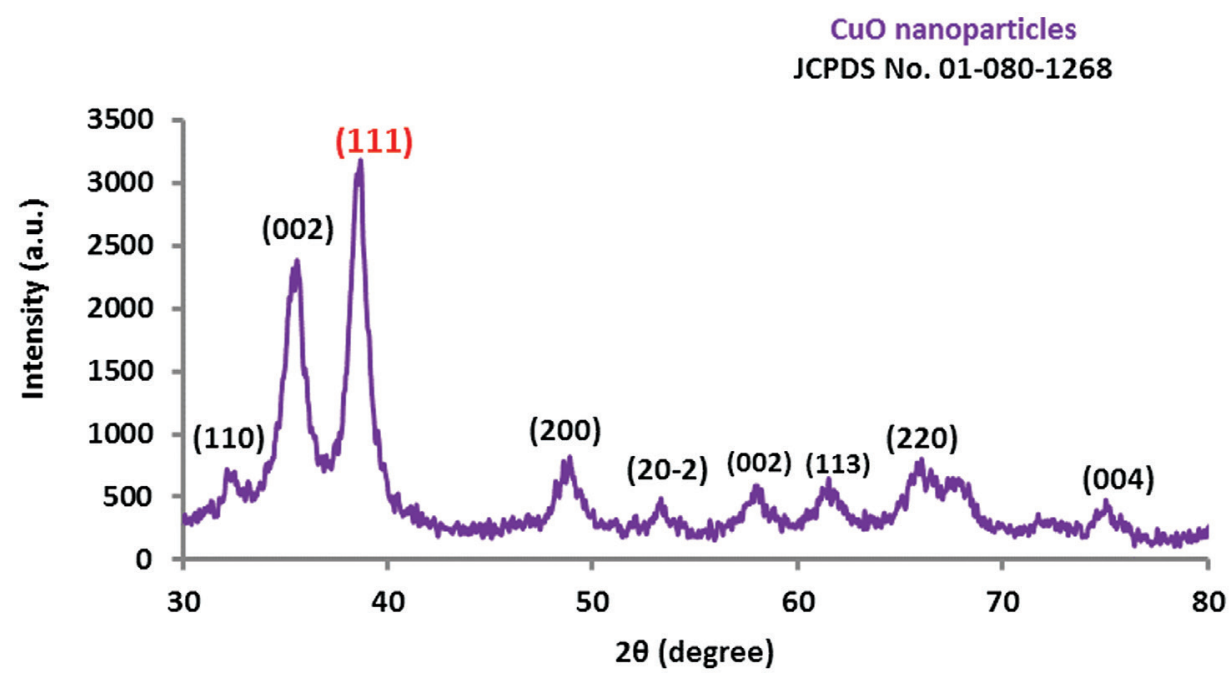

Figure 3: XRD patterns of CuO NPs synthesized by wheat extract.
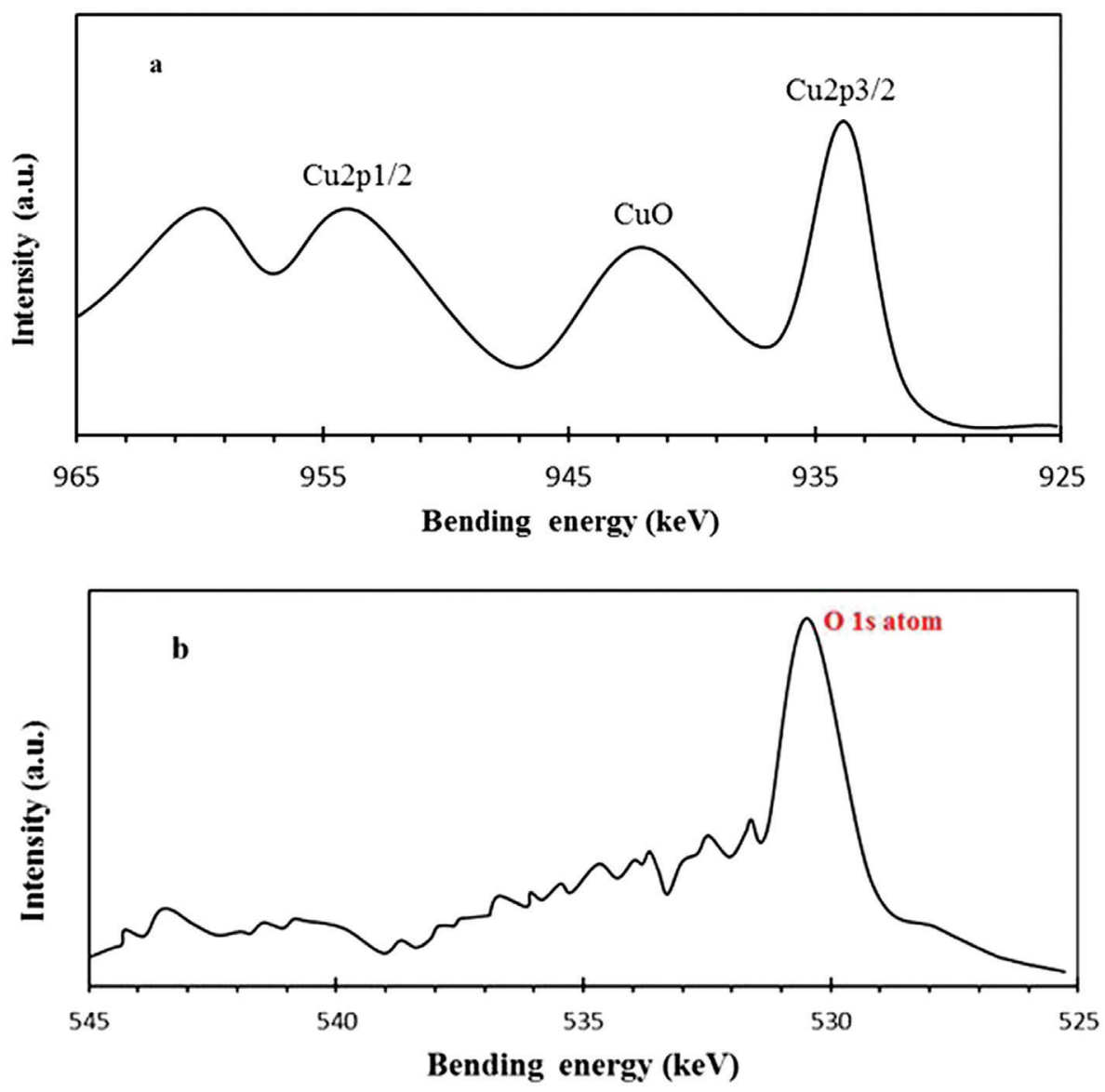

Figure 4: XPS spectra of wheat-mediated CuO NPs, (a) Cu 2P and (b) 01 s. 


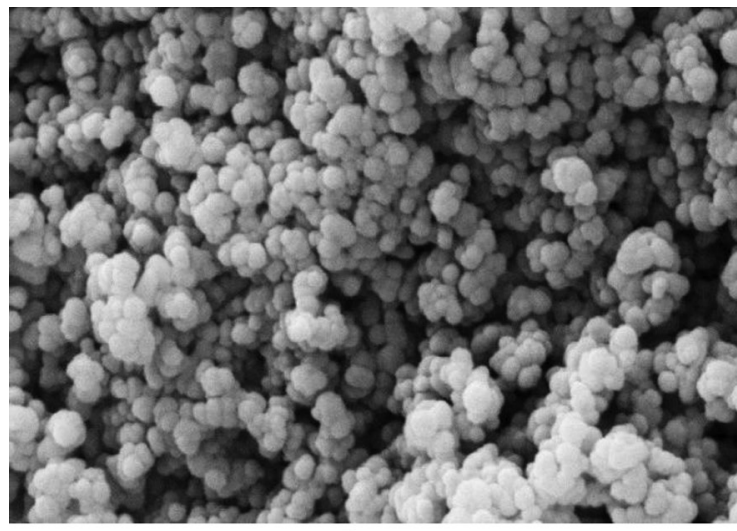

a

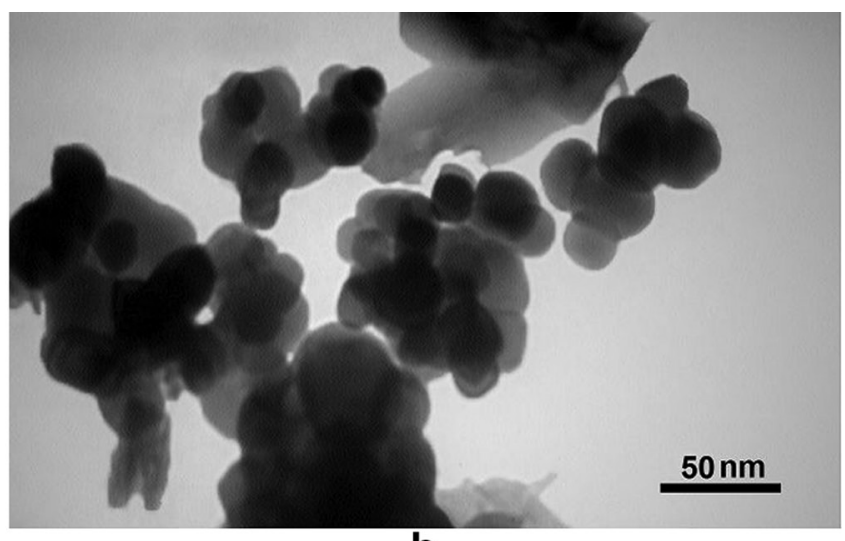

b

Figure 5: (a) SEM image at high magnification (150x) and (b) TEM micrograph of bio-assisted CuO NPs.

[52]. Moreover, according to the XPS results, no $\mathrm{Cu}_{2} \mathrm{O}$ by product was detected in nanoscale $\mathrm{CuO}$ specimen (Figure 4).

\subsection{SEM and TEM characterizations of CuO NPs}

The typical SEM and TEM images of phytosynthesized $\mathrm{CuO}$ NPs was depicted in Figure 5. The SEM results revealed the regular spherical shape with the range size approximately from 21 to $42 \mathrm{~nm}$, confirming the formation of $\mathrm{CuO}$ NPs by aqueous wheat seed extract (Figure 5a). TEM micrograph clearly indicates the biofabrication of CuO NPs with relatively monodispersed spherical shaped particles and diameter of 5-40 nm measured by 300 particles (Figure $5 \mathrm{~b}$ ). The calculated average particle diameter of $\mathrm{CuO}$ NPs was $22 \pm 1.5 \mathrm{~nm}$, supporting XRD results (Figure 3). However, due to sample preparation, slight aggregation of particles has arbitrarily arisen in discrete spots.

\subsection{The mechanism for the formation of CuO nanoparticle}

Scheme 1 is depicted as the tentative mechanism for the preparation of $\mathrm{CuO}$ NPs. Generally, three stages including activation, growth and termination phase could involve in wheat seed-assisted $\mathrm{CuO}$ NPs biosynthesis process (Scheme 2) [53]. In the bioreduction of copper procurer phytochemical compounds presence in wheat seed extract probably function dual role as reducing and capping agents.

In an initial activation step, $\mathrm{Cu}$ (II) cations would extract from $\mathrm{CuSO}_{4}$ salt precursor dissolved in DI water. During mixing progression process, the copper ions react with wheat seed-derived bioorganic compounds such as soluble saccharides via an oxidation-reduction mechanism (Scheme 3). For instance, the abundant electron-rich natural biomolecules containing hydroxyl groups with considerable reduction capabilities would reduce copper cations from divalent oxidation state to metallic form which immediately convert to $\mathrm{CuO}$ NPs as result of the superior chemical reactivity of bare nanoscale copper metal surface. Evidently, the broad peak of $\mathrm{OH}$ of wheat seed extract significantly becomes narrow in FTIR spectrum of CuO NPs indicating an efficient involvement of the alcoholic group in the bioreduction process (Figure 2). In the growth phase, the segregated copper atoms gradually combined to produce $\mathrm{CuO}$ NPs. Finally, in the termination step, stabilization of CuO NPs is developed. Wheat seed-derived natural biomacromolecules such as starch with linear and branched structures would surround the nucleated nanoparticles, creating a protective shield and restricting $\mathrm{CuO}$ NPs from growth [54]. In addition, the steric forces as a result of those biological macromolecules maintain the capped nanoparticles separated from each other, thus prevents them from agglomeration. This finding is in accordance with preceding reports relating to $\mathrm{ZnO}$ and alumina NPs biosynthesis using potato and algal extracts $[55,56]$. Likewise, Poinern et al. indicated that various bioactive compounds present in food waste are key responsible materials for bioreduction metal ions and stabilization of metallic NPs [57].

\subsection{Catalytic activity and reusability of CuO NPs}

The catalytic performance of the biofabricated CuO NPs was examined through measuring the degradation of the organic para-nitrophenol pollutant which is documented 


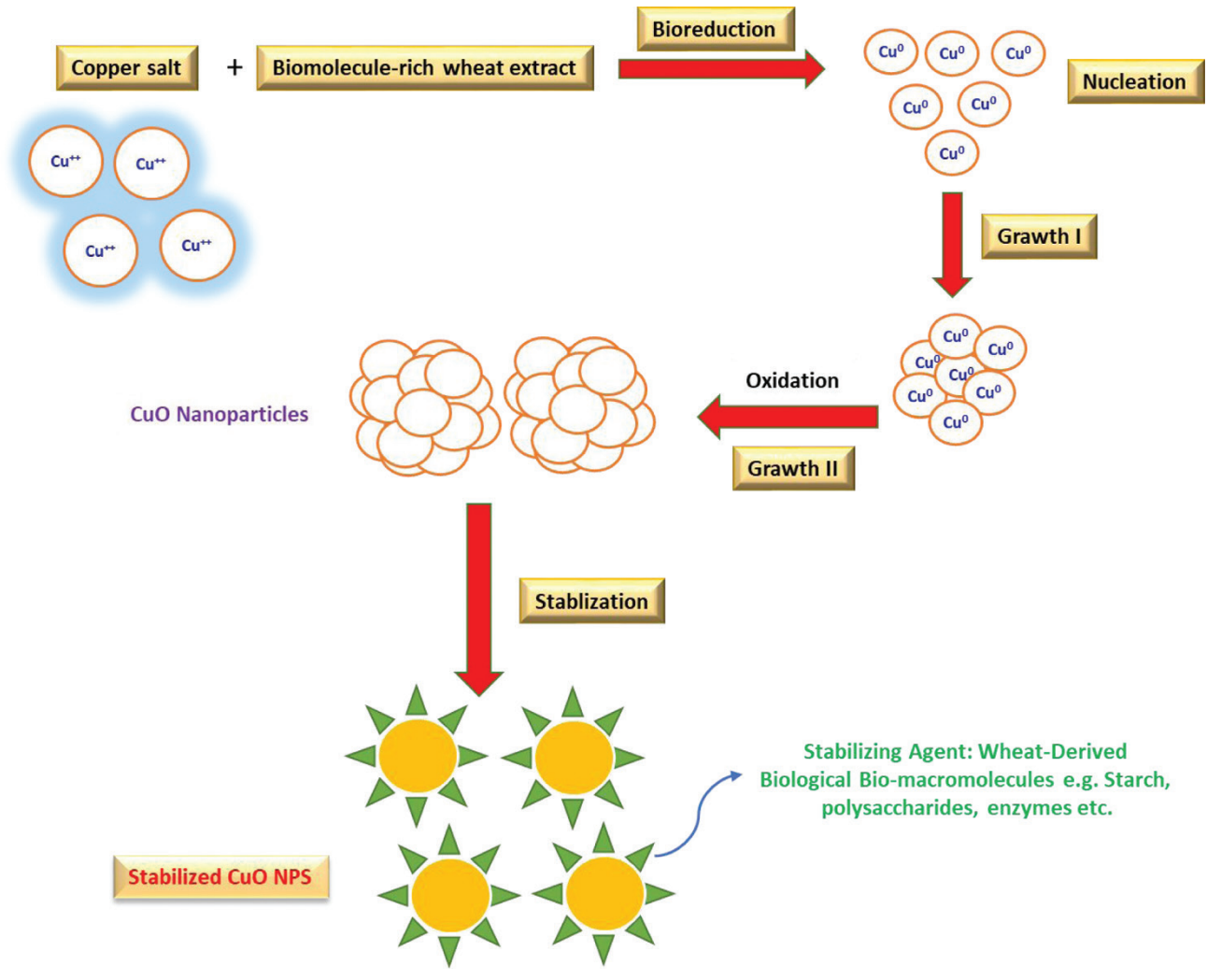

Scheme 2: Illustration of the possible formation mechanism strategy toward biological synthesis of CuO NPs using aqueous extract of wheat seeds.

as a carcinogenic agent to the human being. It is utilized as a precursor for the manufacture of medical products, indicators, and a wide variety of phenetidine and acetophenetidine [58]. Upon the addition of $\mathrm{CuO}$ NPs, the intensity of UV-vis absorption peak of 4-nitrophenol at $315 \mathrm{~nm}$ was completely disappeared within $20 \mathrm{~min}$, thus indicating the rapid adsorptive removal of an organic 4-nitrophenol pollutant from its aqueous solution (Figure 6). Meanwhile, recyclability of CuO NPs performance toward 4-NP degradation was examined in a UV chamber for five days in a raw. It is found that catalytic activity of the $\mathrm{CuO}$ NPs was remarkable (slight changes in removal\%), indicating robustness and reusability of biogenic $\mathrm{CuO}$ NPs for 4-NP elimination (Figure 7).

\subsection{Optimization of CuO NPs synthesis}

Evidently, synthesis optimization of reaction is of paramount importance in obtaining desirable shape and size of bioproduced nanoparticles. Accordingly, the optimization process of crucial criteria including $\mathrm{pH}$, salt concentration, contact time and extract concentration was investigated using UV-vis spectrophotometer. In so doing, different $\mathrm{pH}$ of 3,5 , 7 and 9 was adjusted by $0.1 \mathrm{~N}$ of $\mathrm{HCl}$ and $\mathrm{NaOH}$. The absorbance of the resulting solution exhibit that the rate of $\mathrm{CuO}$ NPs formation accelerates with increasing $\mathrm{pH}$ up to neutral $\mathrm{pH}=7$ and then gradually reduce (Figure S1). The ionization of functional groups highly likely beyond the reduction of nanoparticle production. The concentration of precursor copper salt was optimized by varying copper sulfate solution (10, 30,50 and $80 \mathrm{mM}$ ) in a constant volume of wheat seed extract $(10 \mathrm{~mL})$. Figure S2 has clearly demonstrated that at $50 \mathrm{mM}$ induces the highest amount of $\mathrm{CuO}$ NPs on account of readily availability of $\mathrm{Cu}^{+2}$ cations. In addition, the concentration of the wheat extract was optimized with the increase in the concentration of the wheat extract solution $(10,15,20,25$ and $30 \mathrm{~mL})$. The highest absorption is observed at the slightest amount of aqueous extract of wheat seed $(10 \mathrm{~mL})$, indicating an efficient activity of bioactive molecules present in extract solution (Figure S3). Time variation of green chemical reaction led to the best quality of shape and size of biofabricated $\mathrm{CuO}$ NPs which optimized at a contact time of 25 min (Figure S4). 

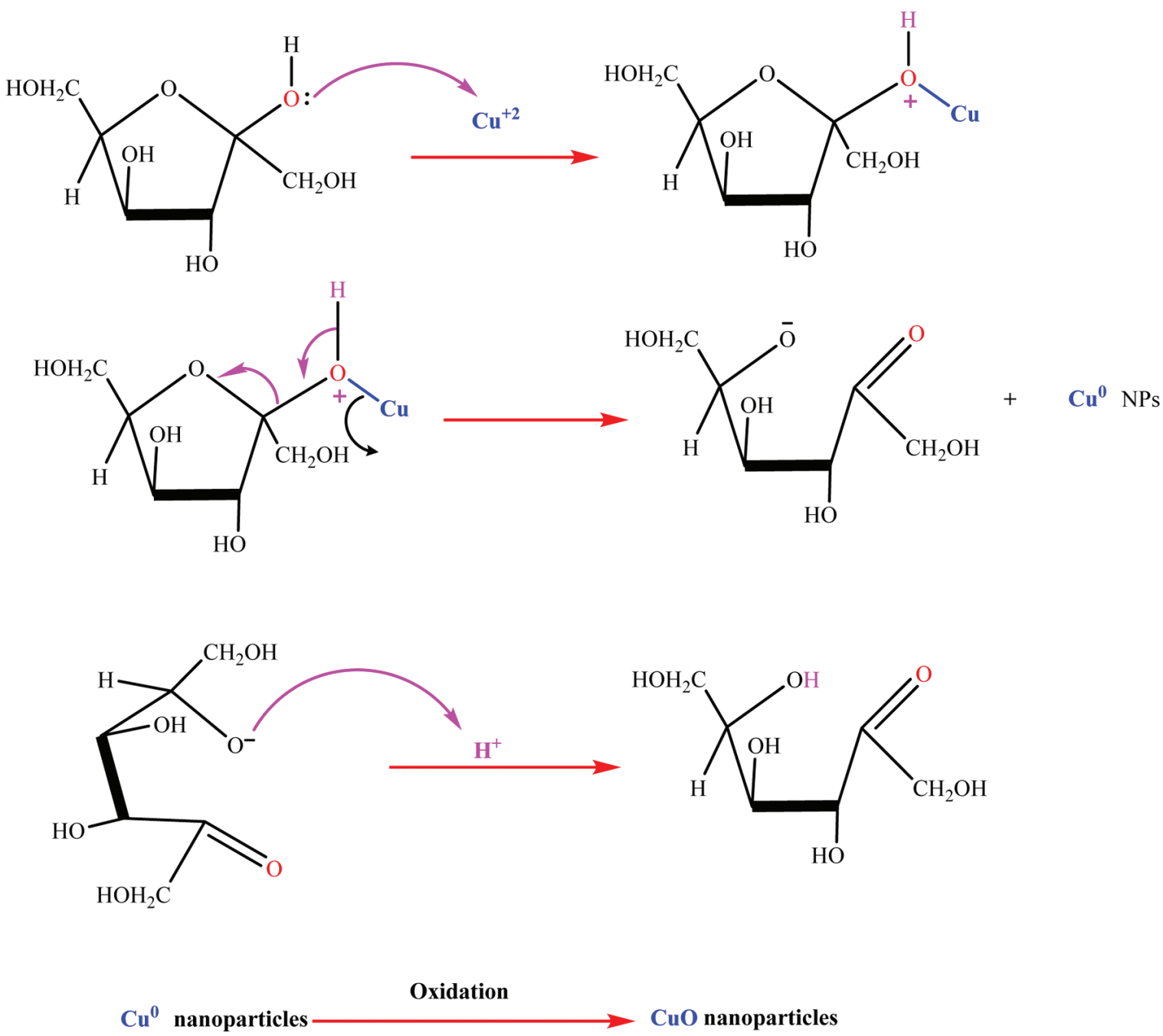

Scheme 3: Schematic illustration of synthetic steps for bioreduction of copper cations using aqueous wheat extract (wheat-derived fructose as bioreducing agent model).

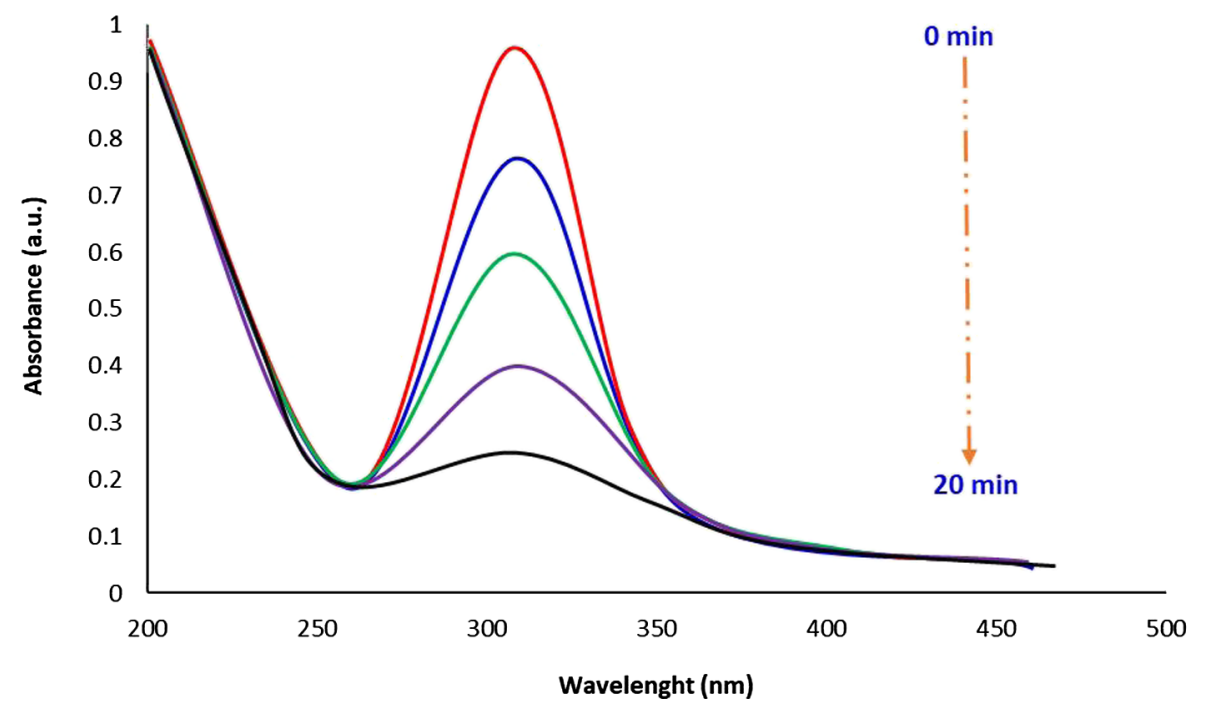

Figure 6: UV-Vis absorption spectral changes during absorption of 4-nitrophenol solution at different times using green CuO NPs. 


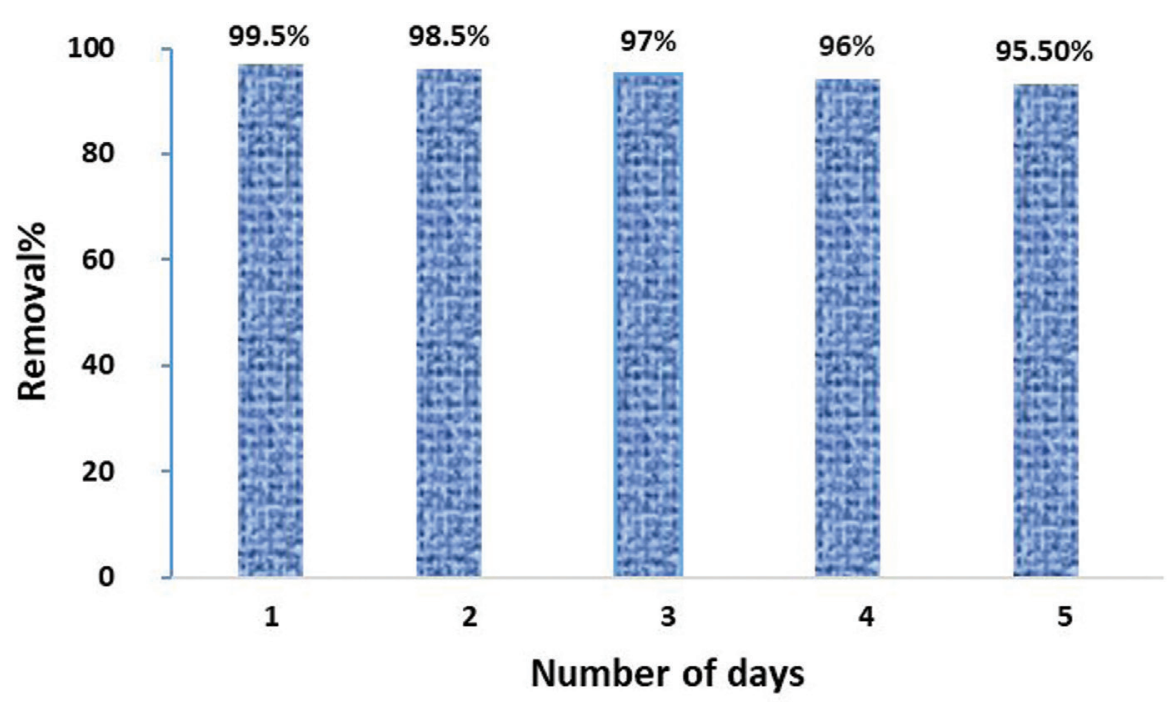

Figure 7: Reusability test of wheat-mediated CuO NPs catalytic efficiency toward 4-nitrophenol pollutant elimination.

\section{Conclusion}

A simple atom-economy green route for biosynthesize highly stable copper nanoparticles through aqueous wheat seed extract was successfully developed. In this assay, the aqueous wheat seed extract of Triticum aestivum showed dual function as reducing and capping/stabilizing agent for the biofabrication of fresh $\mathrm{CuO}$ nanoparticles. Copper oxide nanoparticles were obtained under optimal reaction conditions of neutral $\mathrm{pH}$ and short time of $25 \mathrm{~min}$ at a temperature of $70^{\circ} \mathrm{C}$. All standard techniques including UV-vis, FTIR, XRD, SEM, and TEM confirmed the formation of well dispersed $\mathrm{CuO}$ nanoparticle. The XRD pattern showed $\mathrm{CuO}$ NPs has a monoclinic phase with a crystal size of $20.76 \mathrm{~nm}$. The TEM results indicated the formation of rather spherical NPs with an average diameter of $22 \pm 1.5 \mathrm{~nm}$. Visual observations of $\mathrm{CuO}$ nanoproduct after three months' storage at room temperature show no dispersion, color change or sedimentation, indicating high steric/electrostatic stabilization of wheat seed extract biomolecules. Optimum conditions for the biosynthesis of $\mathrm{CuO}$ NPs are $\mathrm{pH}=7$, the concentration of $\mathrm{CuSO}_{4}, 50 \mathrm{mM}$; wheat extract concentration, $10 \mathrm{~mL}$; and contact time of $25 \mathrm{~min}$. It is found that biogenic CuO NPs exhibited great catalytic efficiency in removal of a toxic 4-nitrophenol pollutant from the contaminated water. Biocompatibility, facile preparation, mild reaction condition, and costeffectiveness of this approach would open a new window to the biogenic synthesis of a wide range of other inorganic nanoparticles. However, large-scale production of nanoparticles would require more research improving the industrial know-how of plant-based synthesis method.
Acknowledgement: This study has been funded by Ghadir Khuzestan Water Company, Ahwaz, Iran (research contract No. ق96/001/118).

Conflict of interest statement: The author declares no conflicts of interest regarding this article.

\section{References}

[1] Duan H., Wang D., Li Y., Green chemistry for nanoparticle synthesis. Chem. Soc. Rev., 2015, 44(16), 5778-5792.

[2] Iravani S., Green synthesis of metal nanoparticles using plants. Green. Chem., 2011, 13(10), 2638-2650.

[3] Khatami M., Alijani H.Q., Nejad M.S., Varma R.S., Core@shell Nanoparticles: Greener Synthesis Using Natural Plant Products. Appl. Sci., 2018, 8(3), 411.

[4] Uddandarao P., Balakrishnan R.M., Thermal and optical characterization of biologically synthesized $\mathrm{ZnS}$ nanoparticles synthesized from an endophytic fungus Aspergillus flavus: A colorimetric probe in metal detection. Spectrochim. Acta A, 2017, 175, 200-207.

[5] Santos A., Troncoso C., Lamilla C., Llanquinao V., Pavez M., Barrientos L., Nanoparticles Synthesized by Antarctic Bacteria and their Possible Mechanisms of Synthesis. Int. J. Morphol., 2017, 35(1), 26-33.

[6] Asmathunisha N., Kathiresan K., A review on biosynthesis of nanoparticles by marine organisms. Colloid. Surface. B, 2013, 103, 283-287.

[7] Singh P., Kim Y.-J., Zhang D., Yang D.-C., Biological synthesis of nanoparticles from plants and microorganisms. Trends Biotechnol., 2016, 34(7), 588-599. 
[8] Gurunathan S., Han J., Park J.H., Kim J.-H., A green chemistry approach for synthesizing biocompatible gold nanoparticles. Nanoscale Res. Lett., 2014, 9(1), 248.

[9] Akhtar M.S., Panwar J., Yun Y.-S., Biogenic synthesis of metallic nanoparticles by plant extracts. ACS Sustain. Chem. Eng., 2013, 1(6), 591-602.

[10] Zhu C., Wang Y., Lu Q., Zhao H., Zhu X., Fa W., et al., Reproduction of Jun-red glazes with nano-sized copper oxide. J. Am. Ceram. Soc., DOI:10.1111/jace.14989.

[11] Gawande M.B., Goswami A., Felpin F.-X., Asefa T., Huang X., Silva R., et al., $\mathrm{Cu}$ and Cu-based nanoparticles: synthesis and applications in catalysis. Chem. Rev., 2016, 116(6), 3722-3811.

[12] Wijesundera R., Fabrication of the $\mathrm{CuO} / \mathrm{Cu}_{2} \mathrm{O}$ heterojunction using an electrodeposition technique for solar cell applications. Semicond. Sci. Technol., 2010, 25(4), 45015.

[13] Zhang J., Liu J., Peng Q., Wang X., Li Y., Nearly monodisperse $\mathrm{Cu}_{2} \mathrm{O}$ and $\mathrm{CuO}$ nanospheres: preparation and applications for sensitive gas sensors. Chem. Mater., 2006, 18(4), 867-871.

[14] Gou X., Wang G., Yang J., Park J., Wexler D., Chemical synthesis, characterisation and gas sensing performance of copper oxide nanoribbons. J. Mater. Chem., 2008, 18(9), 965-969.

[15] Dubey S., Sharma Y.C., Calotropis procera mediated one pot green synthesis of Cupric oxide nanoparticles (CuO-NPs) for adsorptive removal of $\mathrm{Cr}(\mathrm{VI})$ from aqueous solutions. Appl. Organomet. Chem., DOI:10.1002/aoc.3849.

[16] Zhu H.T., Zhang C.Y., Tang Y.M., Wang J.X., Novel synthesis and thermal conductivity of CuO nanofluid, J. Phys. Chem. C, 2007, 111(4), 1646-1650.

[17] Cioffi N., Torsi L., Ditaranto N., Tantillo G., Ghibelli L., Sabbatini L., et al., Copper nanoparticle/polymer composites with antifungal and bacteriostatic properties. Chem. Mater., 2005, 17(21), 5255-5262.

[18] Ben-Moshe T., Dror I., Berkowitz B., Oxidation of organic pollutants in aqueous solutions by nanosized copper oxide catalysts. Appl. Catal. B, 2009, 85(3), 207-211.

[19] Lu F., Astruc D., Nanomaterials for removal of toxic elements from water. Coord. Chem. Rev., 2018, 356, 147-164.

[20] Fan D., Zhou Q., Lv X., Jing J., Ye Z., Shao S., et al., Synthesis, thermal conductivity and anti-oxidation properties of copper nanoparticles encapsulated within few-layer h-BN. Ceram. Int., 2018, 44(1), 1205-1208.

[21] Kuppusamy P., Ilavenil S., Srigopalram S., Maniam G.P., Yusoff M.M., Govindan N., et al., Treating of palm oil mill effluent using Commelina nudiflora mediated copper nanoparticles as a novel bio-control agent. J. Clean. Prod., 2017, 141, 1023-1029.

[22] Assadi Z., Emtiazi G., Zarrabi A., Novel synergistic activities of tetracycline copper oxide nanoparticles integrated into chitosan micro particles for delivery against multiple drug resistant strains: Generation of reactive oxygen species (ROS) and cell death. J. Drug. Deliv. Sci. Tec., 2018, 44, 65-70.
[23] Nagajyothi P., Muthuraman P., Sreekanth T., Kim D.H., Shim J., Green synthesis: In-vitro anticancer activity of copper oxide nanoparticles against human cervical carcinoma cells. Arab. J. Chem., 2017, 10(2), 215-225.

[24] Hans M., Erbe A., Mathews S., Chen Y., Solioz M., Mücklich F., Role of copper oxides in contact killing of bacteria. Langmuir, 2013, 29(52), 16160-16166.

[25] Bala N., Sarkar M., Maiti M., Nandy P., Basu R., Das S., Phenolic compound-mediated single-step fabrication of copper oxide nanoparticles for elucidating their influence on antibacterial and catalytic activity. New J. Chem., 2017, 41(11), 4458-4467.

[26] Yang H., Ouyang J., Tang A., Xiao Y., Li X., Dong X., et al., Electrochemical synthesis and photocatalytic property of cuprous oxide nanoparticles. Mater. Res. Bull., 2006, 41(7), 1310-1318.

[27] Safarifard V., Morsali A., Sonochemical syntheses of a nanosized copper(II) supramolecule as a precursor for the synthesis of copper(II) oxide nanoparticles. Ultrason. Sonochem., 2012, 19(4), 823-829.

[28] Hong Z.-S., Cao Y., Deng J.-F., A convenient alcohothermal approach for low temperature synthesis of $\mathrm{CuO}$ nanoparticles. Mater. Lett., 2002, 52(1), 34-38.

[29] Chen D., Shen G., Tang K., Qian Y., Large-scale synthesis of CuO shuttle-like crystals via a convenient hydrothermal decomposition route. J. Cryst. Growth, 2003, 254(1), 225-228.

[30] Lanje A.S., Sharma S.J., Pode R.B., Ningthoujam R.S., Synthesis and optical characterization of copper oxide nanoparticles. Adv. Appl. Sci. Res., 2010, 1(2), 36-40

[31] Zhao Y., Zhu J.J., Hong J.M., Bian N., Chen H.Y., MicrowaveInduced Polyol-Process Synthesis of Copper and Copper Oxide Nanocrystals with Controllable Morphology. Eur. J. Inorg. Chem., 2004, 2004(20), 4072-4080.

[32] El-Batal Al., El-Sayyad G.S., El-Ghamery A., Gobara M., Response surface methodology optimization of melanin production by Streptomyces cyaneus and synthesis of copper oxide nanoparticles using gamma radiation. J. Clust. Sci., 2017, 28(3), 1083-1112.

[33] Ijaz F., Shahid S., Khan S.A., Ahmad W., Zaman S., Green synthesis of copper oxide nanoparticles using Abutilon indicum leaf extract: Antimicrobial, antioxidant and photocatalytic dye degradation activities. Trop. J. Pharm. Res., 2017, 16, 743-753.

[34] Prasad K.S., Patra A., Shruthi G., Chandan S., Aqueous Extract of Saraca indica Leaves in the Synthesis of Copper Oxide Nanoparticles: Finding a Way towards Going Green. J. Nanotech., DOI:10.1155/2017/7502610.

[35] Bordbar M., Sharifi-Zarchi Z., Khodadadi B., Green synthesis of copper oxide nanoparticles/clinoptilolite using Rheum palmatum $L$. root extract: high catalytic activity for reduction of 
4-nitro phenol, rhodamine B, and methylene blue. J. Solgel. Sci. Technol., 2017, 81(3), 724-733.

[36] Manjari G., Saran S., Arun T., Rao A.V.B., Devipriya S.P., Catalytic and recyclability properties of phytogenic copper oxide nanoparticles derived from Aglaia elaeagnoidea flower extract. J. Saudi Chem. Soc., 2017, 21(5), 610-618.

[37] Jadhav M.S., Kulkarni S., Raikar P., Barretto D.A., Vootla S.K., Raikar U., Green biosynthesis of $\mathrm{CuO} \& \mathrm{Ag}-\mathrm{CuO}$ nanoparticles from Malus domestica leaf extract and evaluation of antibacterial, antioxidant and DNA cleavage activities. New J. Chem., 2018, 42(1), 204-213.

[38] Ochoa L., Medina-Velo I.A., Barrios A.C., Bonilla-Bird N.J., Hernandez-Viezcas J.A., Peralta-Videa J.R., et al., Modulation of CuO nanoparticles toxicity to green pea (Pisum sativum Fabaceae) by the phytohormone indole-3-acetic acid. Sci. Total. Environ., 2017, 598, 513-524.

[39] Xu T., Bian N., Wen M., Xiao J., Yuan C., Cao A., et al., Characterization of a common wheat (Triticum aestivum L.) high-tillering dwarf mutant. Theor. Appl. Genet., 2017, 130(3), 483-494.

[40] D’appolonia B., Rayas-Duarte P., Wheat carbohydrates: structure and functionality. Springer, 1994, 107-127.

[41] Rój E., Dobrzyńska-Inger A., Dębczak A., Kostrzewa D., Stępnik K., Marine Algae Extracts: Processes, Products, and Applications. John Wiley \& Sons, 2015, 101-120.

[42] Felix S., Chakkravarthy R.B.P., Grace A.N., IOP Conference Series: Materials Science and Engineering. IOP Publishing, 2015, 012115.

[43] Abelès F (Ed.), Tauc J., Optical properties of solids. NorthHolland. Publ. Co., 1972, 277, 153.

[44] Bhaumik A., Shearin A.M., Patel R., Ghosh K., Significant enhancement of optical absorption through nano-structuring of copper based oxide semiconductors: possible future materials for solar energy applications. Phys. Chem. Chem. Phys., 2014, 16(22), 11054-11066.

[45] Varughese G., Rini V., Suraj S., Usha K., Characterisation and optical studies of copper oxide nanostructures doped with lanthanum ions. Adv. Mater. Sci. Eng. 2014, 14(4), 49-60.

[46] Kim S.-K., Chojnacka K., Marine Algae Extracts: Processes, Products, and Applications. John Wiley \& Sons, 2015.
[47] Arun K., Batra A., Krishna A., Bhat K., Aggarwal M., Francis J., Surfactant free hydrothermal synthesis of copper oxide nanoparticles. Am. J. Mater. Sci., 2015, 5(3A), 36-38.

[48] Wang H., Xu J.-Z., Zhu J.-J., Chen H.-Y., Preparation of CuO nanoparticles by microwave irradiation. J. Cryst. Growth, 2002, 244(1), 88-94.

[49] Ethiraj A.S., Kang D.J., Synthesis and characterization of CuO nanowires by a simple wet chemical method. Nanoscale Res. Lett., 2012, 7(1), 70.

[50] Alishah H., Pourseyedi S., Ebrahimipour S.Y., Mahani S.E., Rafiei N., Green synthesis of starch-mediated CuO nanoparticles: preparation, characterization, antimicrobial activities and in vitro MTT assay against MCF-7 cell line. Rend. Lincei-Sci. Fis., 2017, 28(1), 65-71.

[51] Tamuly C., Saikia I., Hazarika M., Das M.R., Reduction of aromatic nitro compounds catalyzed by biogenic $\mathrm{CuO}$ nanoparticles. RSC Adv., 2014, 4(95), 53229-53236.

[52] Rovani S., Santos J.J., Corio P., Fungaro D.A., Highly Pure Silica Nanoparticles with High Adsorption Capacity Obtained from Sugarcane Waste Ash. ACS Omega, 2018, 3(3), 2618-2627.

[53] Shamaila S., Sajjad A.K.L., Farooqi S.A., Jabeen N., Majeed S., Farooq I., Advancements in nanoparticle fabrication by hazard free eco-friendly green routes. Appl. Mater. Today, 2016, 5, 150-199.

[54] Raveendran P., Fu J., Wallen S.L., Completely "green” synthesis and stabilization of metal nanoparticles. J. Am. Chem. Soc., 2003, 125(46), 13940-13941.

[55] Buazar F., Bavi M., Kroushawi F., Halvani M., Khaledi-Nasab A., Hossieni S., Potato extract as reducing agent and stabiliser in a facile green one-step synthesis of $\mathrm{ZnO}$ nanoparticles. J. Exp. Nanosci., 2016, 11(3), 175-184.

[56] Koopi H., Buazar F., A novel one-pot biosynthesis of pure alpha aluminum oxide nanoparticles using the macroalgae Sargassum ilicifolium: A green marine approach. Ceram. Int., 2018, 44(8), 8940-8945.

[57] Ghosh P.R., Fawcett D., Sharma S.B., Poinern G.E., Production of high-value nanoparticles via biogenic processes using aquacultural and horticultural food waste. Materials, 2017, 10(8), 852.

[58] Alarcon P., Bustos A., Cañas B., Andres M., Polo L., Determination of priority pollutant phenols by isocratic HPLC. Chromatographia, 1987, 24(1), 613-616. 